\title{
STATE OF THE ART IN THIN FILM TRANSISTOR: A REVIEW OF THE USED INSULATOR-SEMICONDUCTOR COMBINATIONS
}

\author{
ANDRÉ VAN CALSTER and ALEXIS DE VOS \\ Laboratorium voor elektronika en meettechniek, Rijksuniversiteit te Gent, Sint Pietersnieuwstraat 41, \\ B-9000 Gent, Belgium.
}

(Received April 4, 1979)

\begin{abstract}
This paper deals with the technology of the thin film transistor (TFT). It deals with the different semiconductors used successfully in a TFT, as well as the different gate insulators employed. A variety of structures have been realized in the past. The most important difficulty with the use of these TFT structures consisted of low frequency instabilities, caused by mobile ions in the insulator and slow states at the semiconductor-insulator interface. Various proposed solutions to these problems will be discussed.
\end{abstract}

\section{INTRODUCTION}

Already in $1961, ?$. Weimer ${ }^{1}$ realized the first TFT. This insulated gate field effect transistor consisted of a CdS semiconductor film, an $\mathrm{SiO}$ gate insulator film, and $\mathrm{Au}$ electrode films, all evaporated upon a glass substrate, during one single vacuum cycle. Figure 1 shows the geometry of the device. Its operation is familiar to the MOSFET.

With this active thin film device, together with thin film resistors and thin film capacitors, complete circuits could be deposited on an insulating substrate. Recently, interest in such circuits has largely grown, mainly because of potential combination with electroluminescent elements. Large area alphanumeric displays and flat television panels (an alternative to the CRT) are possible applications. ${ }^{2,3,4}$

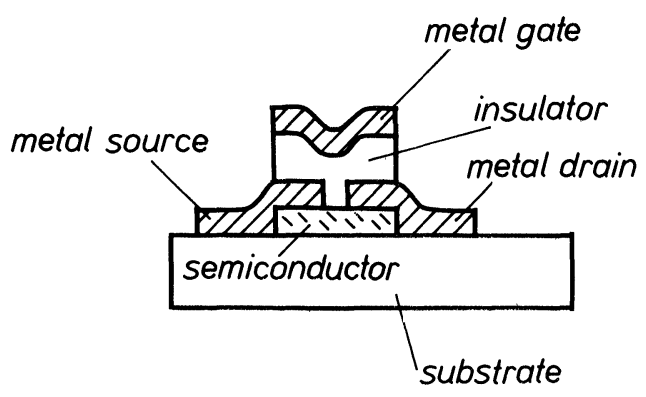

FIGURE 1 TFT geometry.

\section{THE SEMICONDUCTOR FILM}

The semiconductor layer is a thin polycrystalline film of 100 to $1,000 \AA$ thick. A low carrier concentration and a high carrier mobility are desired. In most cases compound semiconductors are evaporated in order to grow the film. Stochiometric films are pursued by heating the substrate during the evaporation or by a post deposition treatment.

Most important are the II-IV compounds $\mathrm{CdS}^{1,5}$ and $\mathrm{CdSe} .^{6,7,8}$ Of these semiconductors CdSe shows the highest-mobility and therefore the highest transistor transconductance. Also important are the III-V compounds InSb ${ }^{9,10}$ and InAs. ${ }^{11}$ Whereas the narrow bandgap $(0.17 \mathrm{eV})$ of InSb makes this material more convenient for low temperature applications, ${ }^{12}$ InAs gives rise to high-gain transistors at room temperature, but needs a 3-temperature evaporation technique. ${ }^{11}$ Further we have the IV-VI compounds $\mathrm{PbS}^{13,14}$ and $\mathrm{Pb}$ Te. 9 Almost all aforementioned semiconductor films have a donor-like doping, and are thus $n$-type. Only $\mathrm{PbTe}$ shows p-type conduction. A more important p-type film however is $\mathrm{Te}^{15}$ It is also the only elemental semiconductor used successfully in TFT. It needs no substrate heating. At last we mention the semiconducting oxides $\mathrm{ZnO}, \mathrm{SnO}_{2}$ and $\mathrm{In}_{2} \mathrm{O}_{3} .{ }^{16,17}$

As an illustration, Figure 2 shows the drain characteristics of 3 TFT's fabricated in the same vacuum plant at our laboratory. Scales are: drain voltage $V_{D}$ horizontally $2 \mathrm{~V} /$ div and drain current $I_{D}$ vertically $0.2 \mathrm{~mA} / \mathrm{div}$. Voltage steps at the gate are 


\section{(a) $\mathrm{CdSe}$ ( $1 \mathrm{~V} / \mathrm{step})$ \\ (b) InSb (2V/ step) \\ (c) $T e \quad(2 V /$ step)}
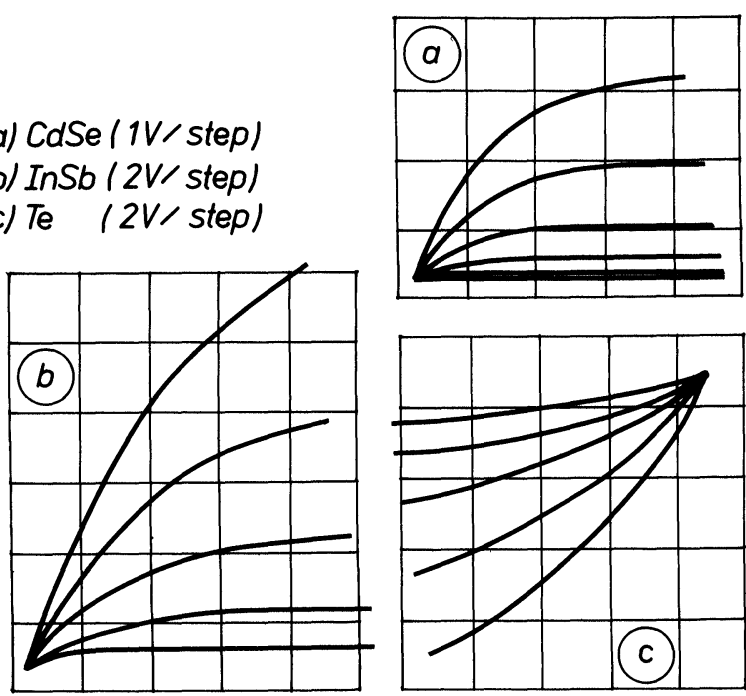

FIGURE 2 TFT characteristics for different semiconductors Horizontal scale: $2 \mathrm{~V} /$ div Vertical scale: $0.2 \mathrm{~mA} /$ div.

indicated between brackets. The semiconductors used, are: CdSe $(500 \AA) \operatorname{InSb}(200 \AA)$ and Te $(130 \AA)$. The insulator is $\mathrm{SiO}$ (respectively $1,000 \AA$, $200 \AA$ and $1,200 \AA$ ).

\section{THE INSULATOR FILM}

For the insulator film, high permittivity and high dielectric strength are desired. Mobile ions have to be avoided (see later). Mostly used is silicon oxide, as in MOS technology. Not only $\mathrm{SiO}_{2}$, but also $\mathrm{SiO}$ and intermediate compositions $\mathrm{SiO}_{x}$ are used. Other suitable oxides are: $\mathrm{Al}_{2} \mathrm{O}_{3}, \mathrm{Dy}_{2} \mathrm{O}_{3}$, $\mathrm{La}_{2} \mathrm{O}_{3}, \mathrm{Yb}_{2} \mathrm{O}_{3}, \mathrm{Nd}_{2} \mathrm{O}_{3}$ and $\mathrm{MgO}$. Also fluorides have been successful: $\mathrm{MgF}_{2}, \mathrm{CaF}_{2}, \mathrm{AlF}_{3}$ and $\mathrm{LiF}$.

Recently, a TFT has been presented with a polymer thin film: polytetrafluoroethylene. ${ }^{18}$

\section{DRIFT}

The most important difficulty with the use of thin film transistors consists of low frequency instabilities (drift phenomena). This is illustrated as follows: suppose one drain characteristic $I_{D}$ versus $V_{D}$ is displayed with a curve tracer. If, at the moment $t=t_{0}$, the gate voltage $V_{G}$ is changed, immediately a new characteristic appears. After this, however, a relaxation mechanism occurs: the new curve drifts towards an equilibrium state. See Figure 3.

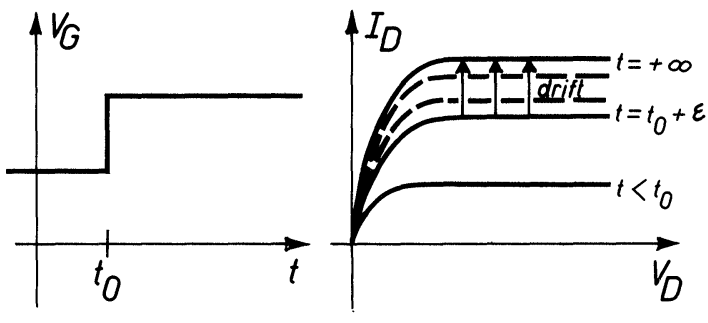

FIGURE 3 Drifting TFT characteristic.

Two phenomena are responsible for this low frequency instability:

a) Mobile ions in the insulator film, who cause a delayed gain of the field-effect (as on Figure 3) and

b) slow states at the interface semiconductorinsulator, which cause a delayed attenuation of the field-effect.

Figure 4 shows the response of the drain current $I_{D}$ (at constant $V_{D}$ ) to a square wave gate voltage (for an $n$-type transistor).

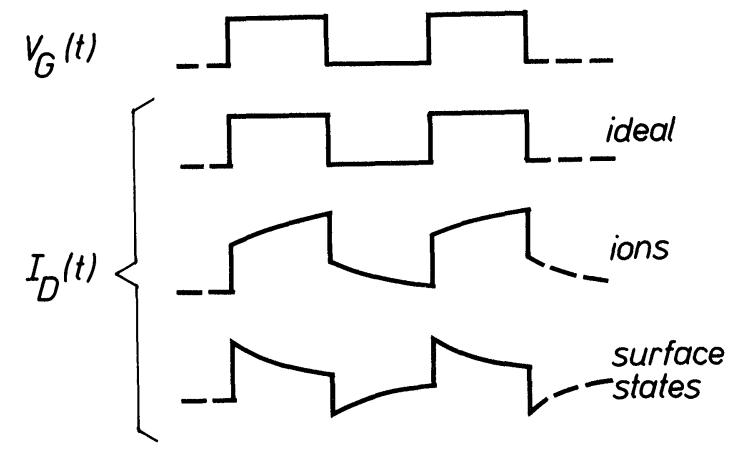

FIGURE 4 Different drain current responses to square wave gate voltage.

For example, an evaporated $\mathrm{SiO}_{x}$ film often contains alkali ions (sodium) and oxygen vacancies, who move through the film, driven by the electric field in the gate capacitor, and cause the first kind of undesired relaxation phenomena. ${ }^{19}$ Analogous effects happen in other dielectrics. The interface of semiconductor and insulator films contain specific electron states. Some of these are filled and emptied with large time constants, what causes the second type of relaxation process. These "surface" states can be located at the interface itself as well as in the insulator. ${ }^{19,20}$ In this last case communication with the electron traps occurs through tunnelling. 


\section{AVOIDING THE DRIFT}

Different methods have been suggested to decrease and even avoid the drift in TFT's. We will discuss here the most important ones:

a) Waxman ${ }^{21}$ suggests the following insulator-semiconductor set: $\mathrm{Al}_{2} \mathrm{O}_{3}-\mathrm{CdSe}$. He first deposits the aluminium gate electrode. This film is then anodized in a dry oxygen plasma to form a layer of $500 \AA$ $\mathrm{Al}_{2} \mathrm{O}_{3}$. Then the $\mathrm{CdSe}$ and source and drain are evaporated, to realize an inverted TFT. An important disadvantage of the technique is the need of a complicated substrate mounting or supplementary photolitographic fabrication steps. Therefore the proposed method deteriorates the main advantage of TFT technology: its simple fabrication process.

b) Recently, Kramer ${ }^{14}$ has suggested the combination $\mathrm{Al}_{2} \mathrm{O}_{3}-\mathrm{PbS}$. The $\mathrm{Al}_{2} \mathrm{O}_{3}$ insulator is evaporated by electron gun, in an oxygen background. The $\mathrm{PbS}$ is evaporated from an indirectly heated boat, also in oxygen background. So, ionic drift instability is eliminated with the use of the $\mathrm{Al}_{2} \mathrm{O}_{3}$ dielectric, whereas the interface density of traps is reduced, probably thanks to the formation of lead oxide near the interface, reducing abrupt discontinuities.

c) Anderson ${ }^{22,23}$ has presented an $\mathrm{SiO}_{2}-\mathrm{CdSe}$ device with long-term stability. Here the way of depositing the $\mathrm{SiO}_{2}$ layer is new: sputtering of quartz.

d) An attractive alternative to the oxides and fluorides seems to be possible thanks to the polymer thin films. De Wilde ${ }^{24}$ has shown that polytetrafluoroethylene films evaporated by electron gun contain no mobile ions. De Vos and Hindryckx ${ }^{18}$ have realized a PTFE-Te transistor with this dielectric. But the transistor showed drift, partly introduced by the high temperature annealing of the transistor. Further research in this field can be interesting, in view of the large spectrum of thin polymer films and the many ways of deposition that can be used. ${ }^{25}$

\section{CONCLUSION}

We may conclude that from the many insulatorsemiconductor combinations, the $\mathrm{Al}_{2} \mathrm{O}_{3}-\mathrm{CdSe}$ and the $\mathrm{Al}_{2} \mathrm{O}_{3}-\mathrm{PbS}$ are the most promising ones. With these combinations stable, drift-free thin film transistors can be made. Both devices have already been used successfully in large complex macrocircuits. ${ }^{2,3}$

The thin film transistor may be considered to be the most suitable device for large area circuits (such as displays) because of the appropriate thin film vacuum technology. But perhaps also in the area of micro-electronics, such as hybrids, the thin film transistor may become an alternative to the monolithic active devices.

\section{REFERENCES}

1. P. Weimer, "The TFT, a new thin-film transistor", Proc. IEE 50 (1962) 1462-1469.

2. T. Brody, F. Luo, Z. Szepesi and D. Davies, "A $6 \times 6$ inch 20 lines-per-inch electroluminescent display panel," IEEE Trans. ED-22 (1975) 739-748.

3. G. Kramer, "Thin-film-transistor switching matrix for flat-panel displays," IEEE Trans. ED-22 (1975) 733-739

4. A. Fisher, "Flat TV panels with polycrystalline layer," Microelectronics 7 (1976) 5-15.

5. C. Neugebauer, D. Miller and J. Hall, "Polycrystalline CdS thin film field effect transistors: fabrication, stability and temperature dependence," Thin Solid Films 2 (1968) 57-78.

6. H. Wilson, and W. Guttierrez, "CdSe thin film field effect transistors," J. Electrochem. Soc. 112 (1965) 85-91.

7. L. Struyf, "The use of radiant heating for evaporating CdSe films," Thin Solid Films 21 (1974) 29-32.

8. A. Van Calster, and H. Pauwels, "Theoretical influence of surface states and bulk traps on thin film transistor characteristics," Solid-St. Electr. 18 (1975) 691-698.

9. D. Lille and J. Anderson, "The application of polycrystalline layers of InSb and PbTe to field-effect transistors," Solid-St. Electr. 12 (1969) 735-741.

10. A. Van Calster, "An experimental study of the InSb thin film transistor," Solid-St. Electr. 22 (1979) 77-80.

11. T. Brody and H. Kunig, "A high-gain InAs thin-film transistor," Appl. Phys. Letters 9 (1966) 259-260.

12. A. Van Calster, "An InSb thin film transistor operating at cryogenic temperatures," Proc. 15th Int. Conf. on Low Temperature Physics, Grenoble (1978) 1186-1187.

13. W. Pennebaker, "PbS thin film transistors," Solid-St Electr. 8 (1965) 509-515.

14. G. Kramer, "Improved stability in $\mathrm{PbS} / \mathrm{Al}_{2} \mathrm{O}_{3}$ thin-film transistors," Techn. Digest Int. IEEE Meeting on Electron Devices, Washington D.C. (1974) 573-575.

15. P. Weimer, "A p-type Te thin-film transistor," Proc. IEEE 52 (1964) 608-609.

16. V. Mokrousov and V. Khanin, "Film-type field triode based on zinc oxide," Izv. VUZ Fizika 14 (1971) 130-131 and Sov. Phys. J. 14 (1971) 534-535.

17. H. Klasens and H. Koelmans, "A tin oxide field-effect transistor," Solid-St. Electr. 7 (1964) 701-702.

18. A. De Vos and B. Hindryckx, "A thin film transistor with polytetrafluoroethylene as insulator," to be published.

19. A. Tickle, Thin-Film Transistors, (J. Wiley, New York, 1969).

20. A. Van Calster, "A channel conductance measuring technique for determining the interface properties of an SiO-InSb thin film transistor," Solid-St. Electr. 21 (1978) 393-401.

21. A. Waxman, "Thin-film transistors don't have to be drifters," Electronics 41 (March 1968) 88-93.

22. J. Anderson, "Thin film transistors," Thin Solid Films 36 (1976) 299-312. 
23. J. Anderson, "Materials properties in thin film transistors," Proc. Int. Conf. on Thin- and Thick-Film Technology, Augsburg (1977) 142-154.

24. W. De Wilde, "Evaporation of polytetrafluoroethylene by electron bombardment of the bulk material," Thin Solid Films 24 (1974) 101-111.

25. M. White, "Thin polymer films," Thin Solid Films 18 (1973) 157-172. 

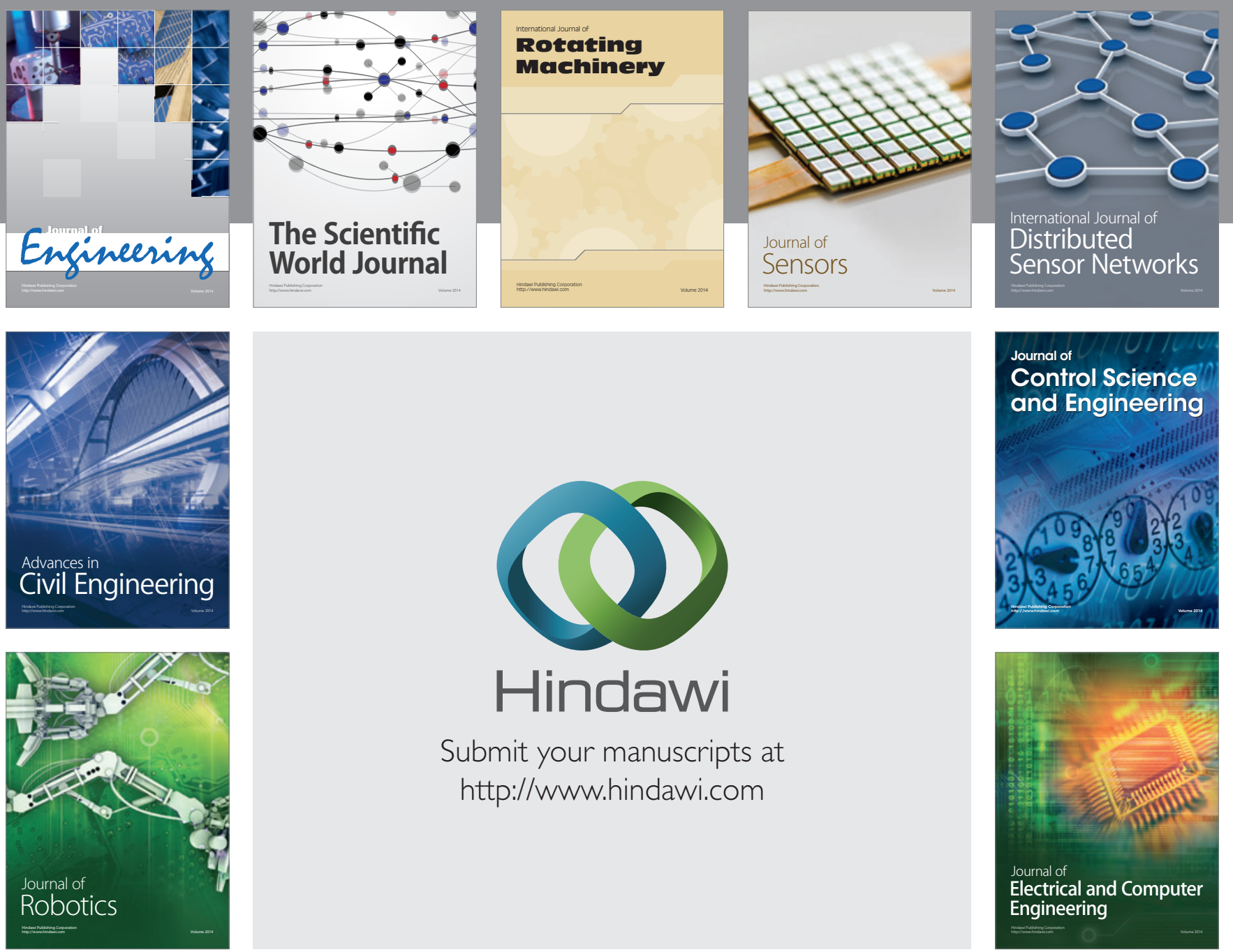

Submit your manuscripts at

http://www.hindawi.com
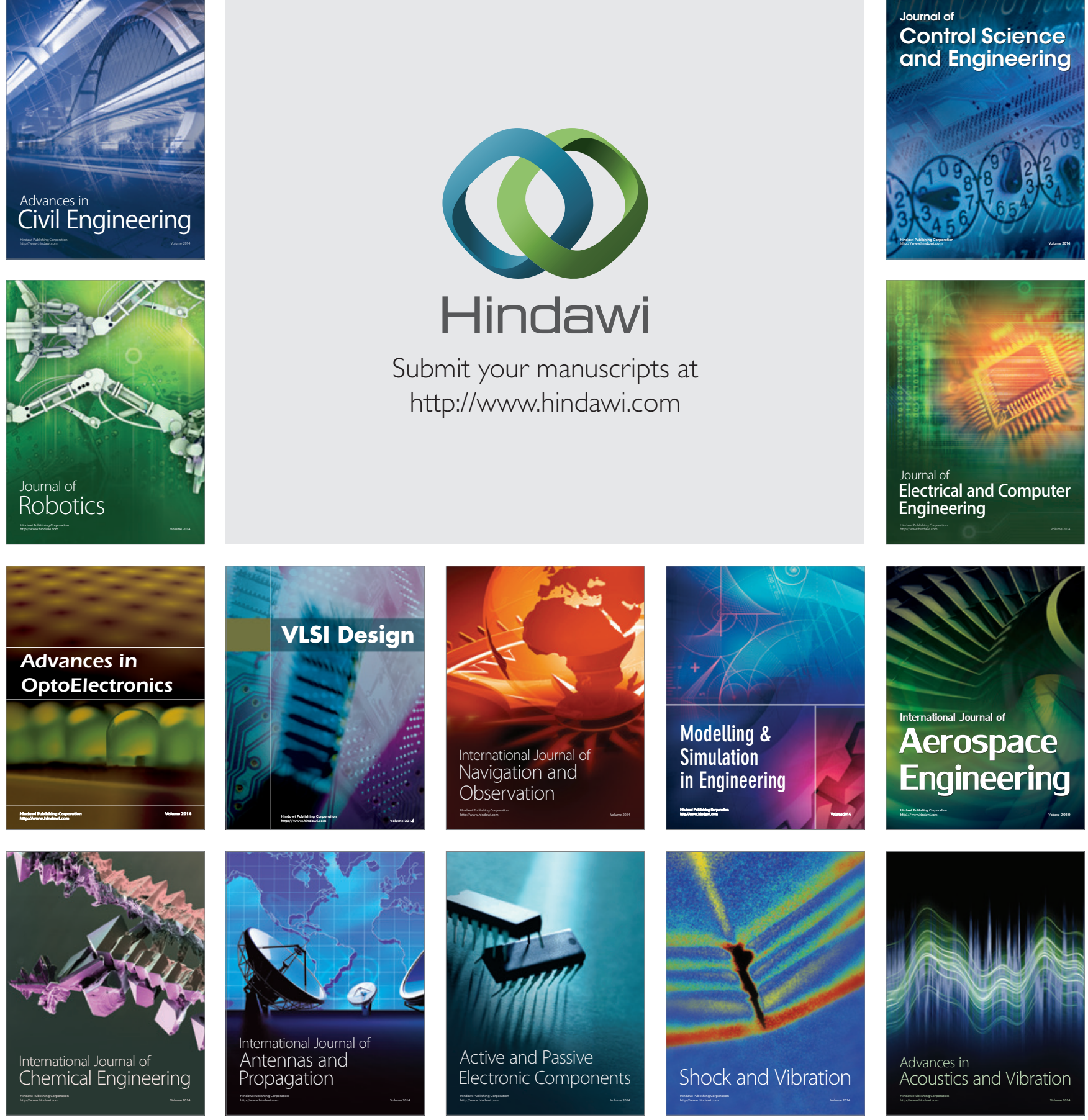